\title{
Memória cultural e o espaço (re)imaginado em Hóspedes da Noite (2007), de Licínio Azevedo
}

Tiago Vieira

Isabel Macedo ${ }^{3}$

\footnotetext{
${ }^{1}$ Este artigo é financiado no âmbito da Knowledge for Development Initiative, pela Rede Aga Khan para o Desenvolvimento e pela FCT - Fundação para a Ciência e Tecnologia, IP ( $n^{\circ}$ 333162622), no contexto do projeto Memories, cultures and identities: how the past weights on the present-day intercultural relations in Mozambique and Portugal?.

2 Tiago Vieira da Silva frequenta atualmente o Doutoramento em Ciências da Comunicação da Universidade do Minho em Braga, Portugal. A sua investigação "O debate da identidade nacional desde a revolução de abril até ao presente, através do cinema português" é financiada pela Fundação para a Ciência e Tecnologia. Licenciou-se em Cinema e Audiovisual na Escola Superior Artística do Porto e frequentou o mestrado em Comunicação, Arte e Cultura na Universidade do Minho, e é membro do projecto Memories, cultures and identities: how the past weights on the present-day intercultural relations in Mozambique and Portugal?, financiado pela Rede Aga Khan para o Desenvolvimento e pela Fundação para a Ciência e Tecnologia. Integra a equipa do Museu Virtual da Lusofonia, no Centro de Estudos de Comunicação e Sociedade.

Email: tiagocamposvieira@gmail.com

${ }^{3}$ Isabel Macedo é doutorada em Estudos Culturais pela Universidade do Minho e Universidade de Aveiro, na área da Comunicação e Cultura. A sua tese intitula-se "Migrações, memória cultural e representações identitárias: a literacia fílmica na promoção do diálogo intercultural", projeto financiado pela Fundação para a Ciência e Tecnologia. É investigadora do Centro de Estudos de Comunicação e Sociedade, tendo integrado projetos nacionais e internacionais, como membro da equipa de investigação. Os seus principais interesses de investigação conjugam as áreas da memória cultural, das migrações, dos media e da comunicação intercultural. Publicou vários artigos em revistas nacionais e internacionais. Email: isabelmaced@gmail.com
} 


\section{Resumo}

O cinema desempenha um papel ativo na formação da nossa compreensão do passado e na definição da agenda para futuros atos de lembrança no seio da sociedade, dado que constitui um meio de memória cultural e visual sobre os países e os espaços e períodos representados. O Grande Hotel da Beira, símbolo de luxo no período colonial, é-nos apresentado, em Hóspedes da noite, por dois ex-funcionários que relembram a sua grandiosidade, enquanto em simultâneo ouvimos os testemunhos dos novos donos que ocupam este espaço, e que reacendem a memória das deslocações forçadas e dos impactos da Guerra Civil em Moçambique. As memórias do período colonial, mesmo não sendo evocadas (não há qualquer referência ao período colonial), assomam na imagem como a emanação fantasmagórica que inscreve o então presente e eiva o futuro - e, neste sentido, revela-se fundamental para os autores uma proposta de reflexão sobre as disputas humanas pela sobrevivência.

Palavras-chave: cinema; memória cultural; espaço; Moçambique.

\section{Abstract}

Cinema plays an active role in shaping our understanding of the past and setting the agenda for future acts of remembrance within society. Films are means of cultural and visual memory about the countries and the spaces and periods represented. Grande Hotel da Beira, a symbol of luxury in the colonial period, is presented to us at Hóspedes da noite by two former staff members who recall its opulence. Simultaneously, the testimonies of the new owners occupying this space rekindle the memory of forced displacement and the impacts of the Civil War in Mozambique. Memories of the colonial period, even when they are not evoked (there is no reference to the colonial period), loom in the image as the phantasmagorical emanation that inscribes the present and affects the future, making the theme of survival the authors' central concern.

Keywords: cinema; cultural memory; space; Mozambique. 


\section{Memória coletiva e os lugares de memória}

Observamos, nos últimos anos, um crescente interesse pela obra de Maurice Halbwachs, sociólogo francês, discípulo de Durkheim, que escreveu os seus principais trabalhos entre as décadas de 20 e 40 do século passado. Halbwachs procurava entender a formação da consciência social, tendo aprofundado o estudo da memória, principalmente em duas grandes obras: Os quadros sociais da memória (1925/1994) e A memória coletiva (1950/1968). Uma ideia transversal à obra de Maurice Hallbwachs consiste na acepção de que a memória individual existe sempre a partir de uma memória coletiva, dado que todas as lembranças são constituídas no interior de um grupo.

Na concepção de Hallbwachs (1950/1968), além das imagens e dos livros, o passado deixou muitos traços, visíveis algumas vezes, e que se percebem também na expressão dos rostos, no aspecto dos lugares e mesmo no modo de pensar e de sentir, inconscientemente conversados e reproduzidos. Para o autor, "é esse passado vivido, bem mais do que o passado apreendido pela história escrita, sobre o qual poderá mais tarde apoiar-se a nossa memória". Hallbwachs (1950/1968: 11) defende que a história vivida "tem tudo o que é preciso para constituir um quadro vivo e natural em que um pensamento pode apoiar-se, para conservar e reencontrar a imagem de seu passado". De acordo com esta perspectiva, a memória individual não é inteiramente isolada e fechada.

De facto, no curso da nossa vida reconhecemos ou lembramos um conjunto de acontecimentos, que na realidade não conhecemos a não ser pelos jornais ou pelos testemunhos daqueles que estiveram envolvidos diretamente nos eventos (por exemplo, a Guerra Colonial). Estes eventos ocupam um espaço na memória da nação, no entanto não assistimos aos acontecimentos. Quando os evocamos recorremos à memória de outros, para completar ou reforçar o nosso discurso. Acumulamos um conjunto de recordações históricas, mesmo das experiências que não vivenciamos, que podemos ampliar pelo diálogo, pela literatura, pelo cinema etc.

De cada período da nossa vida, guardamos algumas lembranças, reproduzidas em contexto social, e "através das quais se perpetua, como que por efeito de uma filiação contínua, o sentimento da nossa identidade" (HALLBWACHS, 1925/1994: 89). Para o autor, uma reconstituição do passado só pode ser uma aproximação. Mesmo que disponhamos de um grande número de testemunhos escritos ou orais, teríamos que evocar o mesmo tempo e todas as influências que se exerceram sobre nós.

O caráter social da memória tem sido objeto de reflexão por inúmeros investigadores e estudos nas últimas décadas, bem como o papel da linguagem no processo de (re)construção identitária pela evocação de memórias. Fentress e Wickham 
(1992) argumentam que a memória é estruturada pela linguagem, por ideias construídas coletivamente e por experiências compartilhadas com outras pessoas.

Quando nos lembramos, representamo-nos a nós próprios para nós mesmos e para aqueles que nos rodeiam. $\mathrm{Na}$ medida em que aquilo que realmente somos pode ser revelado em articulação, nós somos o que lembramos. Se este for o caso, então, um estudo da forma como lembramos - a forma como nos apresentamos nas nossas memórias, a forma como definimos as nossas identidades pessoais e coletivas através das nossas memórias, a nossa forma de ordenarmos e estruturarmos as nossas ideias nas nossas memórias, e a nossa forma de transmitir essas memórias aos outros - é um estudo de quem e como somos. (FENTRESS \& WICKHAM, 1992: 7).

As investigações sobre memória com vítimas de traumas coletivos, como o Holocausto, a guerra ou o colonialismo, evidenciam formas narrativas complexas de construção e reconstrução mnemónica. O modelo tradicional de memória como lugar estático e estável de armazenamento, onde as percepções e experiências passadas são retidas e de onde elas podem ser recuperadas, mostrou-se cada vez mais inadequado e obsoleto. As práticas de memória humanas estão envolvidas em "sistemas de significado, vidas e mundos históricos em ação e interação; são atividades dentro de ordens culturais, que são elas próprias sujeitas a mudanças históricas" (BROCKMEIER, 2010: 27). Uma parte importante dessas ordens culturais são os média, as tecnologias e outros dispositivos com os quais a lembrança humana esteve sempre intimamente ligada.

À medida que a memória tradicional desaparece, observa-se um conjunto de iniciativas para a preservação de vestígios, testemunhos, documentos, imagens, discursos, sinais visíveis do que foi, "como se esse arquivo cada vez mais prolífero se devesse tornar prova em não se sabe que tribunal da história" (NORA, 1997: 159). É o que Nora (1997) designa de lugares de memória - lugares nos três sentidos da palavra: material, simbólico e funcional. Como o autor esclarece, mesmo um lugar de aparência puramente material, como um arquivo, só é lugar de memória se a imaginação o investe de um olhar simbólico. Um lugar funcional, como um manual escolar, um testamento, uma associação de antigos combatentes, só entra na categoria se for objeto de um ritual. Um minuto de silêncio, exemplo de uma significação simbólica, é ao mesmo tempo o recorte material de uma unidade temporal e serve como uma chamada de lembrança. A questão histórica que permeia essa reflexão parece ser a chamada aceleração histórica, 
com os seus desenvolvimentos, transformações incessantes e as suas consequências - a ameaça do esquecimento -, situações que levam a uma obsessão pelo registro, pelos traços, pelos arquivos, em síntese, pela história.

Nas últimas décadas, a memória dilatou-se, "desacelerou-se, descentralizouse, democratizou-se" (NORA, 1997: 15). Como se estivéssemos perante um ímpeto incessante de preservar aquilo que não existirá mais: "arquive-se, arquive-se, sempre sobrará alguma coisa!" (NORA, 1997: 16). Enders (1993: 133) esclarece a noção de lugares de memória do seguinte modo: "o 'lugar de memória' pode ser concebido como um ponto em torno do qual se cristaliza uma parte da memória nacional". O autor considera existir uma imprecisão na noção de lugares de memória, que atravessaria toda a obra de Nora (1997). Na sua opinião, o lugar de memória "possui geometria variável e designa ora objetos, ora um método, ora a memória, ora o trabalho do historiador" (ENDERS, 1993, p. 136).

François Hartog debruçou-se igualmente sobre as insuficiências do conceito de lugares de memória, ao destacar a dificuldade de o mobilizar, no conjunto da obra, para reflexões acerca das suas versões em negativo, os 'não lugares' ou os 'maus' lugares da história ou da memória nacional (HARTOG, 1997). Para o autor, as tensões e a dialética entre memória e esquecimento não teriam sido propriamente examinadas na obra, e os temas incómodos (como o passado da França imperialista e colonizadora) terão sido postos de lado.

O sucesso internacional de Les lieux de mémoire prova que "o mais singular e o mais especificamente cultural é o que mais carrega valores universais" (ENDERS, 1993: 136). Para Enders (1993: 136), dificilmente se poderia fazer algo mais "francofrancês" do que "este trabalho coletivo de introspecção nacional, nascido do sentimento de que uma página secular estava a ser virada, do desejo de desmontar o mecanismo da identidade nacional, da vontade de preservar uma memória que se tornou consciente".

Antologias de textos teóricos, tal como The Collective Memory Reader (OLICK, VINITZKY-SEROUSSI \& LEVY, 2011), bem como o lançamento da revista Memory Studies, testemunham a necessidade de evidenciar essa ampla discussão e "considerar as normas teóricas e metodológicas de um promissor, mas também ainda tão incoerente e disperso campo" (ERLL, 2008: 1). Os estudos da memória cultural não são, portanto, apenas um campo multidisciplinar, mas, fundamentalmente, um projeto interdisciplinar.

A teoria da memória cultural foi introduzida por Aleida e Jan Assmann no final dos anos 80. Um dos principais feitos foi a descrição da relação entre cultura e memória de uma forma sistemática e conceitualmente fundamentada. Em particular, por salientar as interdependências entre memória cultural, identidade coletiva e legitimidade política, 
esta teoria permitiu o desenvolvimento de investigação em vários campos das Ciências Sociais e Humanas (História, Antropologia, Média, Sociologia, etc.). Para os autores há uma diferença qualitativa entre a memória coletiva, baseada em formas de interação e comunicação quotidiana e uma memória coletiva que é mais institucionalizada e apoiada por rituais e pelos média. Os objetos externos, como portadores de memória, desempenham um papel já ao nível de memória pessoal. A memória só existe em interação constante não só com outras pessoas, mas também com coisas, com símbolos exteriores (artefactos, objetos, celebrações, símbolos, filmes). Estes produtos não têm uma memória própria, mas podem desencadear a nossa memória, porque carregam memórias que lhes atribuímos, por exemplo, de festas, rituais, guerras, histórias e textos.

A dinâmica da memória cultural só pode ser plenamente compreendida se tivermos em conta não apenas os fatores sociais, mas também "os 'quadros' de lembrança mediáticos e, especificamente, os processos mediáticos através dos quais as memórias chegam à esfera pública e se tornam coletivas" (ERLL \& RIGNEY, 2009: 2). É na esfera pública que algumas remediações se transformam em versões mediáticas do passado, ao mesmo tempo que outras são ignoradas ou censuradas. Isto significa que a dinâmica da memória cultural deve de ser estudada no cruzamento de ambos os processos - sociais e mediáticos.

Certas ofertas mediáticas tornam-se marcantes na recordação coletiva, e é, em seguida, através da reiteração intermediática dessas narrativas em diferentes plataformas na esfera pública (jornais, internet, rituais comemorativos, filmes), que o tema se enraíza numa determinada comunidade. Com efeito, os média são mais do que transportadores meramente passivos e transparentes de informação, desempenhando um papel ativo na formação da nossa compreensão do passado, na "mediação" entre nós (como os leitores, telespectadores, ouvintes) e entre as experiências passadas, e, portanto, na definição da agenda para futuros atos de lembrança no seio da sociedade (ERLL \& RIGNEY, 2009: 3). Eventos que são lembrados são "fenómenos intermediáticos" (ERLL, 2008: 392), ou seja, a sua representação não está vinculada a um meio específico, podendo ser representados ao longo do espectro dos vários meios disponíveis (filmes, livros, blogues...). E isso pode, precisamente, contribuir para a construção de importantes lugares de memória.

\section{Cinema e espaço (re)imaginado}

O espaço fílmico concentra em si não apenas as dinâmicas inerentes ao processo em que o olho humano apreende o ambiente físico, o demarca, e the atribui significado(s); o espaço fílmico é simultaneamente o espaço (re)criado ou (re)imaginado, constituindo-se um palco de experimentação que sintetiza as potencialidades que o 
dispositivo cinematográfico oferece no que diz respeito às representações da realidade. Isto é, como reflete Carlos Melo Ferreira (2004) a propósito da perspetiva de Béla Balázs, o cinema pode não dar a realidade, mas antes, criar "uma realidade outra, sua, fílmica, que o cineasta constrói com os elementos técnicos e figurativos de que dispõe" (FERREIRA, 2004: 32), acrescentando ainda o autor que "o lugar da criação poética acaba por ser o corpo e o cérebro humano, pela forma como desarticula e articula pessoalmente as imagens que the são proporcionadas, já obedecendo a um recorte físico determinado" (FERREIRA, 2004: 33).

Todavia, cedo o cinema se libertou da percepção natural, fundando, nas palavras de Eduardo Geada, "a descoberta do inconsciente visual" (GEADA, 1985: 10). A descoberta do inconsciente visual será, no entanto, propulsionada pelo próprio cérebro humano, como observou previamente Melo Ferreira (2004), porquanto vai o cinema definir-se a partir da expressão humana inscrita sobre o real (BÁLÀZS, 1985). Esta expressão humana, sôfrega e complexa na sua composição, não obstante nutrir-se do real, carecerá de meios para se materializar, e, ao fazê-lo, distanciar-se-á da perceção humana; ou seja, no processo de construção da sua própria linguagem, o cinema explorará e inaugurará faculdades que, ao libertarem a imagem de um universo concentracionário, como observou Walter Benjamin em $A$ obra de arte na era da reprodutibilidade técnica, descobrirão "outras formas, perfeitamente desconhecidas, que não representam, em absoluto, movimentos rápidos tornados lentos, antes surgem como movimentos fluídos, aéreos, supraterrestres" (BENJAMIN, 1985: 35).

Da constante fascinação pela representação dos distintos espaços, dos distintos modos de vida e da condição humana, o cinema foi-se atualizando, assim, a partir da diversidade e da complexidade espacial (SHIEL, 2001); dessa condição é extraída a matéria a partir da qual vai o cineasta operar a (re)configuração da realidade - e, subsequentemente, como é que esse processo se relaciona com o respetivo contexto social, histórico e cultural. Segundo Mark Shiel, a propósito das representações da cidade no cinema (2001: 1):

Formalmente, o cinema tem há muito uma habilidade distinta de capturar e expressar a complexidade espacial, a diversidade e a dinâmica social da edição, enquanto pensadores desde Walter Benjamin - confrontado com as chocantes novidades da modernidade, da sociedade de massas, a manufatura e a reprodução mecânica - a Jean Baudillard - deslumbrado pelo glamour da pós-modernidade, o individualismo, o consumo e a reprodução eletrónica reconheceram e observaram a curiosa correlação entre a 
mobilidade e as sensações visuais e aurais da cidade, e a mobilidade e as sensações visuais e aurais do cinema.

$\mathrm{Na}$ operação dessas faculdades, vai o cinema convocar o espectador para a contemplação desse imaginário cuja sucessão das imagens ele, por sua vez, não vai dominar, sendo rapidamente submetido pela cadência da projeção (AUMONT \& MARIE, 2011), pois "a todo o momento o filme [lhe] oferece (...) uma importante quantidade de informações sensoriais, cognitivas e afetivas" (AUMONT \& MARIE, 2011: 43). Neste sentido, "os filmes recompõem o humano, a vida, recortam-nos no tempo, afetam-nos e aperfeiçoam-nos, projetam-nos para imaginários pessoais e para imaginários coletivos, e assim agarram-nos para logo de seguida nos largarem" (FERREIRA, 2004: 22). Concomitantemente, vai o espectador operar esse (re)mapeamento a partir de "arquivos individuais e coletivos", como sugerem Jacques Aumont e Michel Marie (2011), porquanto fará existir a imagem recorrendo a uma série de signos e referências visuais. Deste modo, o cinema desconstrói, como observa Sara Castelo Branco, "uma representação cronológica e sequencial do tempo, reconfigurando-o através de uma associação entre várias temporalidades" (BRANCO, 2016: 64), e, neste sentido, cada novo filme "vem re-apanhar-nos na nossa relação com o cinema, encadeando-a com filmes anteriores, passados, com a participação activa da memória, vem re-apanhar-nos na nossa relação com a vida, encadeando-a com a nossa relação com o cinema, de novo com recurso inevitável à memória" (FERREIRA, 2004: 22).

João Mário Grilo e Maria Irene Aparício (2013), a propósito da relação do espectador com o filme, referem a ideia de contágio emocional de Amy Coplan na obra 'Catching Characters' Emotions: Emotional Contagion Responses to Narrative Fiction Film", afirmando que o contágio emocional requer "uma relação sensorial direta (...) porque a visualização das imagens cinematográficas oferece uma experiência sensorial que possibilita os processos automáticos do contágio emocional" (GRILO \& APARÍCIO, 2013: 39), levando o espectador a experienciar uma convergência emocional. Os autores sublinham, a este propósito, o processo em que as técnicas do cinema potenciam esse contágio emocional, como por exemplo o recurso do close-up; isto é, o cinema cria um arquivo próprio que o espectador passará a reconhecer e a interpretar a partir dos seus "arquivos individuais e coletivos", citando novamente Aumont e Marie (2011). Neste sentido, Francesco Casseti observa, em El Film y su Espectador, que o filme abre um espaço que não é um ponto de partida ou uma posição privilegiada, representando ao invés o lugar onde quem entra se reconhece como uma das personagens, processo a partir do qual se relaciona com as mesmas (CASSETI, 2001).

O recurso à memória participa da própria configuração espacial que nos é apresentada pelo filme, porém, é igualmente partilhado pelo espectador, que passará a 
reinterpretar e a ressignificar o universo diegético. É a memória como capacidade humana transformada pelo cinema (desde o uso convencional dos flashbacks ou, mais radicalmente, ao deliberado desajuste espaço-temporal como simulação das dinâmicas do pensamento humano, como Hiroshima, mon amour / Hiroshima, meu amor (1959) ou L'Année Dernière à Marienbad / O Ano Passado em Marienbad (1961), de Alain Resnais), e, simultaneamente, como espaço de partilha com o espectador - é neste sentido que, segundo Carlos Melo Ferreira, se impõe a "necessidade imprescindível de exercício da faculdade da memória, que nos relaciona com tudo, filmes e vida, através do tempo (FERREIRA, 2004: 23).

A este propósito, é importante sublinhar também a ideia de um cinema transnacional, abordagem que, segundo Ruby Cheung e David Fleming (2009), surgiu como uma resposta às limitações no estudo daquilo que o autor denomina como "cinemas nacionais", visto que "muitos filmes contemporâneos lidam com a questão de tentar definir qualquer identidade nacional no contexto de um mundo "globalizado" que é "caracterizado por permutações económicas, culturais e políticas que atravessam fronteiras" (CHEUNG \& FLEMING, 2009: 17). Os autores acrescentam que, em resposta a modos e modelos de cinema que marcaram o final do século $X X$ e início do século XXI, impôs-se a necessidade de aprofundar abordagens relativamente à relação entre o cinema e a(s) identidade(s) (CHEUNG \& FLEMING, 2009). Como observou Catherine Hall (1998: 65):

As mudanças globais dos últimos cinquenta anos envolveram os movimentos de pessoas a uma escala sem precedentes, 0 colapso de impérios e a descolonização, a criação da Nova Europa e outros novos blocos de poder, a destruição de velhas nações e a reformação de outras. As mudanças nesta escala são profundamente desestabilizadoras. Estas promovem o contexto para as tendências contraditórias que nos rodeiam - globalismo, paralelamente ao localismo, os novos nacionalismos e identidades étnicas, paralelamente às vias de comunicação internacionais. Questões como raízes e origens assombram a imaginação de povos distintos, no cruzamento das fronteiras nacionais e intercontinentais.

O processo de revisitação do(s) imaginário(s) representado(s) implica pensar a destruição da cultura dos vencidos e a imposição de medidas de caráter discriminatório, como observou Jorge Seabra, nomeadamente a propósito do imperialismo e a sua estreita relação com o cinema no século XX; o autor sublinha a preocupação dos vencedores em nivelar culturalmente as regiões conquistadas, e, deste modo, 
estabelecer uma ideia de soberania nacional (SEABRA, 2001). No que ao cinema diz respeito, o processo de revisitação dos imaginários num contexto pós-colonial vai marcar-se, segundo Lydie Diakhaté (2011) (referindo-se a autora aos cinemas africanos, nomeadamente ao documentário) por uma ideia de emancipação pela imagem, já não mais inscrita pelo olhar ocidental. Segundo a autora, o olhar etnográfico dos cineastas ocidentais é o primeiro olhar documental pousado sobre África, e, neste sentido, a busca de uma "autenticidade africana" (DIAKHATÉ, 2011: 89) após os processos de independência passou pelo abandono das duas tendências dominantes, "institucionais e etnográficas, em que permaneciam objectos de educação ou de observação" (idem), revelando-se urgente, deste modo, "abandonar a visão dos antropólogos e reencontrar a identidade" (ibidem: 91).

Mahomed Bamba lembra precisamente que os filmes africanos só começam a ser apreciados como imagens de uma outra cultura, "(e não de uma cultura imaginada e pré-fabricada pelo ocidente), quando emerge um novo tipo de público que não compartilha das categorias da crítica eurocêntrica" (BAMBA, 2007: 85). Hóspedes da Noite perscruta um universo que urge essa revisitação, propondo uma reflexão fundada na relação entre a linguagem cinematográfica e os temas dominantes, nomeadamente o peso do passado, a memória (que se constrói a partir dos testemunhos de diferentes personagens) e a experiência presente - iluminando-se, assim, o exercício em que o cinema reivindica o seu papel enquanto meio que reconfigura permanentemente, não apenas o(s) imaginário(s), mas também a própria forma de se comunicar com o espectador na exploração sucessiva e inventiva das suas faculdades.

\section{Hóspedes da Noite: narrativas sobre o passado e o presente no Grande Hotel da Beira}

A ideia de cinemas transnacionais (CHEUNG \& FLEMING, 2009) e de novas formas estéticas e políticas no processo de reencontro da identidade (DIAWARA \& DIAKHATÉ, 2011), ao inscrever livremente a História dos países africanos posteriormente à sua independência, permite-nos estabelecer correspondência entre os processos de experimentação cinematográfica e os processos de afirmação da(s) identidade(s) - nomeadamente, a partir da obra que nos propomos analisar neste artigo: o filme Hóspedes da Noite (2007), de Licínio de Azevedo; e, nesse processo, desvendar a relevância da representação espacial e o papel construtor da memória enquanto relação a partir da qual vai o cinema evidenciar a sua capacidade de urdir e contestar representações identitárias, e, ao mesmo tempo, propor reflexões em torno das experiências histórico-culturais que reconfiguram permanentemente o(s) imaginário(s). 
No âmbito deste artigo, revela-se fundamental evocar a ideia de fetichismo colonial enquanto encenação do fascínio e do desejo que impregna as representações de lugar(es), e a forma como essas fantasias sobre o outro são continuamente perpetuadas (BHABHA, 1998; HOOKS, 1992). Propõe-se, deste modo, uma subversão do olhar, a partir da assunção de que a cultura ocidental consolidou o fetichismo das demais culturas como factos inertes da natureza, como preludiou Edward Said (2003) a sua obra Orientalismo. O autor, refletindo acerca da perceção ocidental do Oriente, observa que (2003: 3):

Temos de levar a sério a grande observação de Vico de que os homens fazem a sua própria história, de que o que eles podem conhecer é aquilo que fizeram, e devemos aplicá-la também à geografia: esses lugares, regiões e setores geográficos que constituem o Oriente e o Ocidente, enquanto entidades geográficas e culturais - para já não dizer históricas - são criações do homem.

O apelo de Edward Said reveste-se de considerável importância para o processo de desconstrução das mitologias de lugar, das ideias fixas e saturadas de identidades, isto é, das "criações do homem" (SAID, 1998: 3), que subjugaram seres humanos e espaços, e, consequentemente, ditaram as suas experiências históricas, sociais e culturais. Neste sentido, o filme Hóspedes da Noite estabelece um espaço - o Grande Hotel Beira ${ }^{4}$ - cuja memória simbólica (remetendo ao passado colonial) é permanentemente reconfigurada pelos corpos que nele habitam (três mil e quinhentas pessoas que ocupam todas as divisões, incluindo a cave, os corredores e o terraço). lluminando as várias histórias destes residentes e as suas relações sociais, centradas na cooperação e na sobrevivência, mas também as suas dissidências, Hóspedes da Noite reivindica essa pretensão de desconstrução espaço-temporal servindo-se tão-só das imagens do quotidiano prosaico - cabendo ao espectador, deste modo, (re)interpretar essa simbiose entre corpos, memórias e espaços que sustenta - e vai reconfigurando - o universo fílmico. Hóspedes da Noite insere-se entre o documentário e a ficção, relação que será subsequentemente problematizada.

Licínio Azevedo, nascido no Rio Grande do Sul (Brasil) e radicado em Moçambique em 1975, trabalhou com Ruy Guerra e Jean-Luc Godard no Instituto

\footnotetext{
${ }^{4}$ O Grande Hotel, fundado em 1955, e localizado na cidade da Beira, capital da província de Sofala, fazia parte de uma zona turística, objeto de propaganda colonial, que associava a este espaço a ideia de Éden, de paraíso tropical junto ao Índico. Resultou, tal como o porto e o caminho-de-ferro, de um investimento financeiro na arquitetura e na organização urbanística durante a época colonial (FRANÇA, 2017; SPINUZZA, 2018).
} 
Nacional de Cinema ${ }^{5}$ (INC, criado em 1975, por Samora Machel), tendo estabelecido, posteriormente, uma empresa de produção cinematográfica, a Ébano Multimédia. Realizou filmes como $A$ árvore dos antepassados (longa-metragem, ficção, 1995), $A$ guerra da água (longa-metragem, ficção, 1996), Desobediência (longa-metragem, ficção/documentário, 2002), O Grande Bazar (longa-metragem, ficção/documentário 2006), Hóspedes da noite (longa-metragem, documentário/ficção, 2007) e Virgem Margarida (longa-metragem, ficção, 2012). Os filmes do realizador têm por base os pontos de vista da população sobre a sua realidade, constituindo um cinema engajado socialmente (BAMBA, 2011). Os documentários $A$ árvore dos nossos antepassados e Hóspedes da noite abordam o tema da guerra civil e as suas consequências. Estas obras destacam e põem em cena a palavra e as ações das pessoas comuns, questionando, em simultâneo, as dimensões histórica, social e política de uma realidade que reflete problemáticas atuais, como as marcas da guerra civil e a pobreza extrema.

Em Hóspedes da Noite, a ausência da narração em off serve o propósito de não admitir uma interferência entre o espectador e a imagem fílmica, no sentido em que 0 universo diegético comunica com o espectador através do movimento dos corpos no espaço - desde os testemunhos de Cairo e Pires, ex-funcionários do hotel durante o período colonial, aos relatos dos moradores - não apenas das relações entre eles, no quotidiano presente, mas também das evocações pessoais que reacendem a memória das deslocações forçadas e dos impactos da Guerra Civil. A improvisação, que se constitui uma particularidade central da mise-en-scène de Licínio de Azevedo (como verificamos nas sequências em que as personagens narram as suas experiências pessoais, passadas ou presentes), corresponde-se diretamente com a dimensão documental da obra, que coloca em confronto esses painéis diversos da vivência diária dos moradores, de forma que seja acentuado um distanciamento claro de um rigor de encenação.

São duas as perspectivas com as quais nos confrontamos em Hóspedes da Noite. Por um lado, as histórias do quotidiano presente dos moradores do hotel; por outro lado, o olhar de dois antigos funcionários que relembram o passado glamoroso daquele espaço. A narrativa dos antigos funcionários, que circulam na atual estrutura do hotel, "são elementos de conexão entre duas épocas históricas e representam uma memória colonial totalmente apagada pelos escombros atuais" (SPINUZZA, 2018: 167). É verdade que a memória sustém um espírito de resistência, como observa Bell Hooks, na esteira de Michel Foucault, porém, acrescenta a autora que "na cultura do

\footnotetext{
5 "Entre 1976 e 1991, o INC produziu treze longas-metragens, 119 curtas-metragens e 295 reportagens
} televisivas batizadas com o nome Kuxa Kanema ("Nascimento do Cinema")" (LOPES, 2016: 7). 
esquecimento, a memória por si só não possui qualquer significado" (HOOKS, 1992: 193).

Licínio Azevedo não parece investir numa tradição cinematográfica que procura equilibrar a ficção e o documentário com o propósito de imprimir à narrativa uma hibridez propositada - como se verifica, por exemplo, com o cinema de Pedro Costa; em Hóspedes da Noite, a câmara é assumida como elemento cuja presença vibra na diegese, é pressentida e percecionada pelos corpos. Todavia, existem sequências que parecem aniquilar essa percepção, nomeadamente quando Camões, o professor de geografia que nós sabemos viver, à data, há 20 anos no hotel, conversa com a mulher relativamente à resposta favorável à sua candidatura a docente numa universidade (Hóspedes da Noite, 2007, 00:44:28-00:45:02):

“- Aqueles documentos que meti, de candidatura, para lecionar na Universidade Pedagógica em Quelimane, saíram favoráveis (...). Neste caso, no próximo ano teremos que mudar para Quelimane"

- Será que a UP vai te ceder uma casa?

- Terei que alugar uma casa onde os miúdos vão estar num quarto independente, diferente de como a gente vive aqui

- É uma cidade linda. Vai ser bonito. Nossos filhos vão crescer bem."

Nesse momento, a câmara parece deixar de ser pressentida, deixando os corpos entregues à privacidade do seu espaço - instala-se, momentaneamente - e, para nossa surpresa, a encenação, que nós acabamos por reconhecer como um recurso que visa expor o espaço mais íntimo das personagens, a fim de que o espectador se possa corresponder com as suas inquietações pessoais.

Em Hóspedes da Noite, Licínio de Azevedo parece repercutir na narrativa a tradição do documentário enquanto género "em que deve prevalecer o princípio da realidade, das coisas tal como elas são, do documentado", como diz-nos Carlos Melo Ferreira (FERREIRA, 2011: 135), não obstante o autor acrescente que este pressuposto é uma contradição, porquanto "o documentário cinematográfico existiu, existe e continuará a existir como procura por diversos métodos da realidade das coisas e dos seres, mas uma procura humanamente perseguida e construída, como no cinema sempre acontece" (FERREIRA, 2011: 135). O autor justifica (FERREIRA, 2011: 136):

Quando se fala em narrativa no documentário não se está a falar na narrativa no sentido geral do cinema de ficção, mas de uma narrativa que serve os propósitos do documentário sem os desvirtuar. É, desde Flaherty e Vertov, algo que excede os 
meros acontecimentos, já presentes nos primeiros filmes dos Lumière, mas que não se propõe, em geral, mais que animar a descrição documental, tornando-a mais viva sem a afastar dos seus objetivos específicos, o que é claramente visível em Nanook.

Refletimos acerca do processo de criação artística do documentário a fim de analisarmos os trilhos percorridos por Licínio de Azevedo na construção do universo diegético como espaço de memórias e vivências que se correspondem simbioticamente entre passado e presente. Manuela Penafria observa que o documentário não se confunde nem deve ser identificado com a não-ficção, pois, apesar de os documentários serem filmes de não-ficção, nem todos os filmes de não-ficção são documentários, e, neste sentido, "a utilização do termo não-ficção deve servir, não para designar o documentário, mas para o incluir num conceito lato e flexível que reconhece diferentes formas de fazer filmes" (PENAFRIA, 1999: 21). Novamente relembramos as palavras de Carlos Melo Ferreira a propósito da sua descrença na defesa da não-manipulação na criação cinematográfica, pois a linguagem cinematográfica é povoada por elementos fundamentais "que implicam, todos eles, uma escolha ou mais que uma escolha humana, [que] estão também presentes no documentário, seja ele rodado em película para cinema, seja ele rodado em vídeo para cinema, televisão ou outro media" (FERREIRA, 2011: 135).

Licínio de Azevedo não manipula o discurso das personagens, dispondo-se a ouvi-las e a inscrever o seu discurso na narrativa, mesmo que as mesmas se limitem a relatar aspectos triviais da sua convivência - o vizinho que suja o espaço do outro, os moradores que caíram na escadaria e morreram - que, por vezes, nem evocam as memórias mais possantes que pairam sobre aquele espaço: o período colonial, quando o hotel foi construído, a guerra civil moçambicana e a deslocação forçada de várias comunidades. Todavia, essas memórias, mesmo quando não são evocadas, assomam na imagem como a emanação fantasmagórica que inscreve o então presente e eiva o futuro, fazendo com que a preocupação central e exclusiva das personagens seja a sobrevivência; nas intermitências desse processo, brilha ocasionalmente a felicidade, com as crianças que se lançam na busca dos ninhos de pássaros e correm pelos corredores do hotel (Hóspedes da Noite, 2007, 00:34:18-00:34:43), com a ténue esperança que resplandece nos olhos de Camões perante a hipótese de mudar de vida.

É nesse quotidiano que o espectador reconhece as consequências do passado, que afetam diretamente a vida diária dos moradores, condenados pelas precárias condições de saneamento e pela escassez de alimentos e de água. Vejamos a sequência do "tribunal", em que conhecemos as próprias estruturas criadas pela 
comunidade a fim de colmatar as consequências advindas dessas condições (Hóspedes da Noite, 2007, 00:36:46-00:37:42):

"- Senhor Moisés, queixa contra quem?

- Contra essa senhora.

(...)

- Senhora Susana António, o que se passou?

- Essa senhora lançou água suja na minha varanda.

- Esse senhor sempre atira água suja na minha casa, na minha varanda. Xixi, cocó, água de peixe na minha varanda. Eu fiquei farta. Levei aquela água e fui deitar na porta dele, para ver se ele também podia sentir. E sentiu, tinha que vir queixar."

Neste sentido, as memórias individuais vão sendo constantemente inscritas no(s) espaço(s) do hotel, com as distintas histórias de vida dos vários moradores, os seus problemas pessoais, fazendo da memória um lugar de depósitos vários, em permanente construção, pois, como observa Jan Assmann, "toda a memória individual constitui-se em comunicação com os outros. Estes "outros", contudo, não são um qualquer grupo de pessoas, mas grupos que concebem a sua unidade e peculiaridade através de uma imagem comum do seu passado" (ASSMANN, 1995: 127). É, segundo as palavras de Jens Brockmeier, um espaço simbólico onde o ser humano se corresponde com uma comunidade cultural, isto é, a partir de uma força centrípeta de uma estrutura conetiva que organiza "um considerável corpo de pensamento e conhecimento, crenças e conceitos do eu: isto é, uma mundividência enraizada num quadro de regras sociais e valores assim como na memória partilhada de um passado comummente habitado e semelhantemente experienciado" (BROCKMEIER, 2002: 18). Segundo o autor (2002: 37):

A ideia que eu quero oferecer sobre este sistema mnemónico é a de um espaço simbólico de recordação e esquecimento, um espaço onde as várias ordens do passado e do presente são continuamente recombinadas. Já sugeri (...) que é dentro deste espaço simbólico de cultura que as nossas coordenadas de mudança para determinar o que é passado, presente e futuro são definidas.

Sobre a memória colonial que reveste o Grande Hotel Beira justapõem-se, deste modo, outras memórias posteriores, que se vão acumulando como camadas que reconfiguram a própria identidade cultural da comunidade que aí habita; o seu reconhecimento do espaço dá-se, consequentemente, pela interpenetração de memórias e experiências que alteram permanentemente o todo. Hewer e Roberts (2012) 
observam, a este propósito, que a natureza da memória coletiva é influenciada no processo de transformação e partilha geracional, já que este fenómeno permite "mudanças subtis e mudanças de ênfase nas narrativas individuais através das gerações ao longo do tempo: algo que foi observado em famílias em que parentes mais velhos se envolveram em guerras questionáveis" (HEWER \& ROBERTS, 2012: 177). Ao mesmo tempo, os autores enfatizam que (2012: 175):

o resultado da interação entre história, memória coletiva e experiência individual é um único sentido da realidade e da identidade: um estado que é, ainda assim, vulnerável à mudança enquanto o individuo interage com o mundo social. Dentro do meio social, a comunicação, o "coração e sangue" que perpassam as dinâmicas da memória social, é informada por ambas as entidades estáticas e dinâmicas.

É a partir dessa partilha geracional que as histórias distintas se entretecem, relacionando-se as experiências individuais na configuração de um coletivo perpassado por transformações e mudanças várias. O Grande Hotel Beira assome, assim, como espaço de disputa e sobrevivência onde se impôs a necessidade de salvaguardar a vida coletiva e social, objetivo que pressupõe a existência de normas e regras cruciais para a subsistência da comunidade que o habita, como as estruturas de controle dos inquilinos - e é nessa luta contínua que as personagens se destacam como corpos que consolidam memórias, memórias que, por sua vez, consolidam histórias que circunscreveram um espaço, conferindo-lhe, permanentemente, significado(s) a partir da pluralidade de experiências humanas.

\section{Notas finais}

Os fenómenos que perpassam e propulsionam o(s) exercício(s) da memória readaptam-se ao contexto histórico, cultural e social, destacando-se o cinema como meio de representação - a partir da complexidade da linguagem cinematográfica - das questões subjacentes a esse processo. Como verificamos, o filme Hóspedes da Noite, enquanto exercício audiovisual ancorado no documentário, pretende iluminar a subjetividade das personagens, evidenciar a sua voz como elemento que (re)configura a diegese e ao mesmo tempo permite ao espectador interpretar as suas memórias e experiências individuais a partir do que ele próprio sabe: do peso da memória colonial à memória da guerra civil e dos deslocamentos forçados, o espectador reconstrói esse espaço-tempo a partir das perspetivas individuais, dos sujeitos pensantes que partilham abertamente as suas experiências - pois, para Licínio de Azevedo, é a voz desses seres 
humanos que importa evidenciar, são eles que possuem o papel de desbravar e traduzir aquele universo ao qual pertencem, e o qual inscrevem continuamente.

Filmes como Hóspedes da Noite constituem lugares de memória e de (re)construção histórica, em particular, porque expressam uma memória visual e olhares, não raras vezes, esquecidos ou ignorados pela história, eurocêntrica, e pela memória oficial. Importa indagar se filmes como aquele analisado neste artigo constituem lugares de memória dominados ou dominantes (Nora, 1997), examinando a visibilidade social destes trabalhos, o que poderá ser alcançado pela realização de estudos de receção. A transformação de filmes como Hóspedes da noite em lugares de memória dominantes poderá contribuir para a desconstrução da memória social e do imaginário colonial.

\section{Referências bibliográficas}

ASSMAN, Jan. "Collective Memory and Cultural Identity". New German Critique, Cultural History/Cultural Studies, No. 65, Spring - Summer, 1995, 125-133.

ASSMANN, Jan. "Communicative and Cultural Memory". In: A. Erll \& A. Nunning (Eds.), Media and Cultural Memory. Berlim, Nova lorque: Walter de Gruyter, 2008.

AUMONT, Jacques \& MARIE, Michel. A análise do filme. $1^{\text {a }}$ edição. Lisboa: Edições Texto e Grafia, 2011.

BAMBA, Mahomed. "O papel dos festivais na recepção e divulgação dos cinemas africanos". In: MELEIRO, Alessandra (Org.). Cinema no mundo: indústria, política e mercado: África. São Paulo: Escrituras, 2007, pp. 79-104.

BAMBA, Mahomed. "O parti-pris ideológico e estético de dois brasileiros na formação de um cinema pós-colonial em Moçambique (anos 70-80)". Interin, 12(2), 1-11.

BENJAMIN, Walter. BÁLÀZS, Béla. EISENSTEIN, Sergei. et al. Estéticas do Cinema. Lisboa: Publicações Dom Quixote, 1985.

BHABHA, Homi. O Local da Cultura. Belo Horizonte: Editora UFMG, 1998.

BRANCO, Sara Castelo. "O Cinema Português, o Transtemporal e o Mito". Aniki: Revista Portuguesa Da Imagem Em Movimento, 3(1), 2016, 64-83.

BROCKMEIER, Jens. After the Archive: Remapping Memory. Culture \& Psychology, 16(1), 2010, 5-35. doi: 10.1177/1354067X09353212

BROCKMEIER, Jens. "Remember and Forgetting: Narrative as Cultural Memory. Culture \& Psychology, 8(1), 2002, 15-43.

CASSETI, Francesco. El Film y su Espectador. 2ª edição, Madrid: Cátedra, 1996.

CHEUNG, Ruby \& FLEMING, David (Eds.). Cinemas, Identities and Beyond. Newcastle upon Tyne: Cambridge Scholars Publishing, 2009. 
DIAKHATÉ, Lydie. "O documentário em África e na sua diáspora: uma emancipação pela imagem". In: DIAWARA, Manthia. DIAKHATÉ, Lydie. Cinema africano: novas formas estéticas e políticas. Lisboa: Sextante Editora, 2011.

DIAWARA, Manthia. DIAKHATÉ, Lydie. Cinema africano: novas formas estéticas e políticas. Lisboa: Sextante Editora, 2011.

ENDERS, Armelle. Les Lieux de Mémoire dez anos depois. Estudos Históricos, 6(11), 1993, 132-137.

ERLL, Astrid. \& RIGNEY, Ann. Introduction: Cultural Memory and its Dynamics. In A. Erll \& A. Rigney (Eds.)., Mediation, Remediation, and the Dynamics of Cultural Memory (pp. 1-14). Berlim, Nova lorque: Walter de Gruyter, 2009.

ERLL, Astrid. Literature, film, and the mediality of cultural memory. In A. Erll \& A. Nunning (Eds.), Cultural Memory Studies: An International and Interdisciplinary Handbook (pp. 389-398). Berlim: Walter de Gruyter, 2008.

FENTRESS, James \& WICKHAM, Chris. Social Memory. Oxford: Blackwell Publishers, 1992.

FERREIRA, Carlos Melo. As poéticas do cinema: a poética da terra e os rumos do humano na ordem do fílmico. Lisboa: Edições afrontamento, 2004.

FERREIRA, Carlos Melo. Cinema. Uma arte impura. Lisboa: Edições Afrontamento, 2011.

FRANÇA, Alex. A produção documentarista de Licínio de Azevedo: imagens, discursos e narrativas moçambicanas do pós-independência. Mulemba, 9(17), 2017, 99-111.

GRILO, João Mário. APARÍCIO, Maria Irene. (Eds). Cinema e Filosofia. Compêndio. Lisboa: Edições Colibri, 2013.

HALL, Catherine. "Histories, empires and the post-colonial moment". In: CHAMBERS, Ian. CURTI, Lidia. The post-colonial question. London and New York: Routledge, 1998. HALLBWACHS, Maurice. La mémoire collective. Paris: Presses Universitaires de France, 1950/1968.

HARTOG, François. O tempo desorientado - Tempo e História. Como escrever a história da França? Anos 90, 5(7), 1997, 7-28. Disponível em: http://www.seer.ufrgs.br/index.php/anos90/article/view/6183/13479.

HEWER, Christopher. ROBERTS, Ron. "History, culture and cognition: towards a dynamic model of social memory". Culture \& Psychology. 18(2), 2012, 167-183.

HOOKS, Bell. Black Looks: Race and Representation. Boston, Massachusetts: South End Press, 1992.

LOPES, José. Cinema de Moçambique no pós-independência: uma trajetória. RebecaRevista Brasileira de Estudos de Cinema e Audiovisual, 5(2), 2016.

NORA, Pierre. Les lieux de mémoire: la République, la Nation, les France. França: Gallimard Éditions, 1997.

OLICK, Jeffrey.; VINITZKY-SEROUSSI, Vered \& LEVY, Daniel (Eds.). The Collective Memory Reader. Oxford: Oxford University Press, 2008. 
PENAFRIA, Manuela. O filme documentário: história, identidade, tecnologia. Lisboa: Edições Cosmos, 1999.

SAID, Edward. Orientalismo. Lisboa: Livros Cotovia, 2004.

SEABRA, Jorge. África Nossa. O Império Colonial na Ficção Cinematográfica Portuguesa: 1945-1974. Coimbra: Imprensa da Universidade de Coimbra, 2001.

SHIEL, Mark; FITZMAURICE, Tony. Cinema and the city. Film and urban societies in a global context. Oxford: Blackwell Publishers, 2001.

SPINUZZA, Giulia. O ciclo do Grande Hotel da Beira: os documentários Grande Hotel, de Lotte Stoops; Grande Hotel, de Anabela Saint-Maurice; Hóspedes da noite, de Licínio de Azevedo e Amanhecer a Andar, de Sílvia Firmino. Remate de Males, 38(1), 2018, 161-185. 